\title{
Personality Traits Of Teachers And Their Attitude Towards Inclusive Education
}

\author{
Hemadharsini. R, Jerald. A, Amutha. J, \\ Kendriya Vidyalaya, No2, Madurai. \\ DOI: 10.29322/IJSRP.11.01.2021.p10972 \\ http://dx.doi.org/10.29322/IJSRP.11.01.2021.p10972
}

\begin{abstract}
Inclusive Education is defined as a learning environment that promotes the full personal, academic and professional development of all learners irrespective of race, class, gender, disability, religion, culture, sexual preference, learning styles and language. ((NCSNET1998) and (NCESS 1998). The aim of the current research is to study on the relationship between teachers' attitude towards inclusive education and personality among teachers working in kendriya Vidyalaya, Madurai. The objective of the study is to find out the level of teacher's attitude towards inclusive education, to find out the personality trait of the teachers and to find out the relationship between personality trait and teachers' attitude towards inclusive education. The study incorporates descriptive research design. Since the research adopted a census survey method the entire population was consider as a sample. The size of the sample is 84. The nature of the population is teachers working in Kendriya Vidyalaya, Madurai. Teachers Attitude Scale towards Inclusive Education (TASTIE) developed by Dr. Vishal Sood and Dr. Arti nand and Big Five personality Inventory (BFPI) developed by Dr. Arun Kumar Singh and Dr. Ashok Kumar were employed for collection of data. The study concludes that there is no significance correlation between neuroticism, extraversion, openness, agreeableness, conscientiousness and Teachers attitude towards inclusive education.
\end{abstract}

Index Terms- Attitude, Inclusive education, Personality trait, Teacher

\section{INTRODUCTION}

Inclusive Education is embracing all (NCF-2005). Inclusive education is embracing all types of children in the school irrespective of any social, community, caste, gender and disability of the child. The fundamental principle of Inclusive Education is that all children should have the opportunity to learn together (NCSE, 2015). Inclusive Education means that all students in a school, regardless of their strengths or weaknesses in any area, become part of the school community. They must be made to have the feeling of belongingness among other students, teachers, and support staff.

The challenges confronting the school system while including children with diverse abilities and backgrounds have to be solved by creating a child-centred pedagogy to successfully educate all children. Inclusive Education is about restructuring the cultures, policies and practices in schools and in education system so that the right to education of all kind of children to study under one roof is achieved.

The necessities and significance of inclusive education are differentiated instruction, reduced stigma, effective use of resources, basis for inclusive society, human resource capitalisation, better academic performance, development of leadership skills, parental involment, building self-esteem and self-worth and economical.

If inclusive education is to be the focus of educational policy in near future, the reciprocal role of regular teachers and special teachers would be crucial (Julka, 1998). Teachers feel inclusion as desirable but not feasible on account of large class size, vast curriculum content, lake of training to teachers, lake of awareness among the teachers to deal with special children and rigid curriculum (Zaveri, 2001).

From the review of literature, it was found that teacher's role in inclusive education is vital. It is only through open hearted, open minded, committed and true teacher that special children can be included in regular or normal classroom with other general children (Vishal Sood, 2000). Only such teachers can bring disabled students in the main stream of the society so that they can contribute their optimum for betterment of society and nation as a whole (Anand, 2000). So, it can be said that teacher's attitude towards inclusive education is very important. Therefore, researcher wanted to study about teachers' attitude towards inclusive education, and thought of assessing the personality of teachers also to find whether there is relation between them.

Personality is defined as "the dynamic organization within the individual of that psychophysical system that determines his/her characteristics behaviour and thoughts" (Allport, 1961). Researcher reviewed the literature and found that personality dimension openness is in a positive correlation with the attitude towards inclusive education (Jelisaveta Todorovic, 2011). Primary school teachers have more positive attitude towards inclusive education (Jelisaveta Todorovic, 2011). Another literature shows that there existed significant difference between male and female teachers' attitude towards inclusive education (Manju Jain, 2017). Teachers with introversion personality type have found to have a favourable attitude towards inclusive education (naik, 2015). 
From the review of literature, it was found that there is a smaller number of studies done on this population which is teachers of kendriya Vidyalaya, Madurai and based on these two following tools such as Teachers Attitude Towards Inclusive Education and Big Five Personality Inventory. The dimensions of personality also differ from previous research to that of the current study.

\section{AIM}

To study on the relationship between personality traits of the teachers and their attitude towards inclusive education among teachers working in kendriya Vidyalaya, Madurai.

\section{OBJECTIVE}

1. To find out the level of teacher's attitude towards inclusive education.

2. To find out the personality trait of the teachers.

3. To find out the relationship between personality trait and teachers' attitude towards inclusive education.

\section{HYPOTHESIS}

There is significance difference between personality trait and teachers' attitude towards inclusive education.

\section{METHODOLOGY}

The study incorporates descriptive research design. Since the research adopted a census survey method the entire population was consider as a sample. The size of the sample is 84 . The nature of the population are teachers working in Kendriya Vidyalaya, Madurai. The data was collected by using a standardized Questionnaires. The questionnaire that were used in the current study are "Teachers attitude towards inclusive education" was developed by Dr. Vishal Sood. It is a 40-item questionnaire that measures the level of attitude towards inclusive education and "Big Five Personality Inventory" was developed by Dr. Arun Kumar. It is a 180 items questionnaire which measures the dimension of personality.

\section{DATA ANALYSIS}

The collected data was analysed by using SPSS. Pearson Correlation analysis were used to verify the hypotheses.

VII. RESULT AND DISCUSSION

Table 1: Showing the Mean value of Teachers Attitude Towards Inclusive Education

\begin{tabular}{lc}
\hline Variables & Mean \\
\hline Attitude & 113.27
\end{tabular}

From the table 1, it is apparent that most of the teacher's attitude towards inclusive education is above average favourable.

Table 2: Showing the Mean value of Teachers Attitude Towards Inclusive Education across age, gender and years of experience.

\begin{tabular}{ll}
\hline Variables & Mean value of attitude \\
\hline Age: & \\
$19-40$ & 113.67 \\
$40-65$ & 112.57
\end{tabular}

\begin{tabular}{ll}
\hline Years of experience: & \\
$1-11$ & 113.85 \\
$12-23$ & 110.00 \\
$24-35$ & 114.19
\end{tabular}

\section{Gender:}

Male

Female

From the above table it is clear that irrespective of the age, gender and years of experience the attitude towards inclusive education was found to be above average favourable.

Table 3: Showing the Mean value of Dimensions of personality

\begin{tabular}{lc}
\hline Variables & Mean \\
\hline Neuroticism & 48.18 \\
Extraversion & 61.58
\end{tabular}




$\begin{array}{lr}\text { Openness } & 61.39 \\ \text { Agreeableness } & 64.48 \\ \text { Conscientiousness } & 64.33\end{array}$

Table 3 shows that, most of the teacher's personality dimension such as neuroticism is moderate, extraversion is high, openness is high, agreeableness is high and conscientiousness is high.

Table 4: Showing the Correlation of Attitude and Dimensions of personality

\begin{tabular}{llllll}
\hline Variables & Neuroticism & Extraversion & Openness & Agreeableness & Conscientiousness \\
\hline Attitude & & & & & \\
P value & 0.846 & 0.377 & 0.164 & 0.150 & 0.193 \\
r value & 0.021 & 0.098 & 0.153 & 0.158 & 0.144
\end{tabular}

It is clear from the above table that, there is no significance correlation between dimensions of personality (neuroticism, extraversion, openness, agreeableness and conscientiousness) and teachers' attitude towards inclusive education.

\section{REFERENCE:}

[1] Azjen I. (2005). Attitudes, personality and behavior. New York: Open university press. Second edition.

[2] Al-Zyoudi M. (2006). Teachers' Attitudes towards Inclusive Education in Jordanian Schools. International Journal of Special Education. vol.21(2). pp- 55-62.

[3] Baron R.A. Branscombe N. R. Byrne D.E. (2008). Social psychology. Boston. MA:

Pearson/Allyn and Bacon.

[4] Bendova P. Cechackova M. Sadkova L. (2014). Inclusive Education of Pre-school Children with Special ducational. Procedia-Social and Behavioural Sciences. 112. 1014-1021.

[5] Bentea C. (2015). Relationships between personality characteristics and attitude towards work in school teachers. ProcediaSocial and Behavioural Sciences. 180. 1562-1568.

Castello S. and Boyle C. (2013). Pre-service Secondary Teachers' Attitudes Towards Inclusive

Education. Australian Journal of Teacher Education. vol.38(4). pp-128-143.

[6] Dutta J. Banerjee D. (2013). Inclusive Education: attitude and problems as perceived by the secondary school students. Indian Journal of Educational Research. vol. II. pp- 125-132.

\section{Authors Detail:}

1. Hemadharsini. R. M.Sc. (Psychology). dharsini.psychologist@gmail.com

2. Jerald. A. M. Com, M.Phil., M.Ed., MBA, M.Sc. (Counselling and Psychotherapy), PG Diploma in Guidance and counselling.jeraldkvs@gmail.com

3. Amutha. J. M.Sc. (maths), B.Ed. 22amuthaj@gmail.com 